\title{
ANATOMIA DA MADEIRA DE DUAS ARALIÁCEAS DA FLORESTA ESTACIONAL DE MISIONES, ARGENTINA
}

\author{
Graciela I. B. de Muñiz \\ Departamento de Engenharia e Tecnologia Rurais - CCA \\ UFPR - Curitiba, PR \\ José Newton Cardoso Marchiori \\ Departamento de Ciências Florestais - CCR \\ UFSM - Santa Maria, RS
}

\section{RESUMO}

São descritas as madeiras de Didymopanax morototonii (Aubl.) Dcne. \& Planch. e Pentapanax warmingianus (March.) Harms, em seus aspectos gerais e microscópicos. As duas espécies assemelham-se quanto aos caracteres mais importantes, referidos na literatura para a família Araliaceae. Didimopanax morototonii apresenta pontoações intervasculares ornamentadas, geralmente em arranjo escalariforme e com placas de perfuração escalariformes nos vasos. Pentapanax warmingianus distingue-se pelas pontoações intervasculares não ornamentadas, de forma arredondada ou poligonal e pelas placas de perfuração predominantemente simples.

Palavras Chave: Anatomia da Madeira, Araliaceae, Didymopanax

morototonii, Pentapanax warmingianus. 


\section{SUMMARY}

The wood anatomy of Didymopanax morototonii (Aubl.) Dene. \& Planch. and Pentapanax warmingianus (March.) Harms. are studied in their general and microscopic features. Both species share the most important anatomical features, described in the literature for the Araliaceae family. Didymopanax morototonii presents vestured and mostly scalariform pits and scalariform perforation plates in vessel members. Pentapanax warmingianus, on the other hand, does not have vestured pits and shows round or polygonal pits and mostly simple perforation plates in vessel members.

Keywords: Wood Anatomy, Araliaceae, Didymopanax morototonii, Pentapanax warmingianus.

\section{INTRODUÇÃO}

A família Araliaceae compreende cerca de 70 gêneros e 700 espécies (MELCHIOR, 1964) de árvores, arbustos, trepadeiras e plantas herbáceas, que se distribuem principalmente pelas regiões tropicais do mundo. A flora neotropical inclui 8 gêneros: Aralia, Dendropanax, Didymopanax, Oreopanax, Pentapanax, Pseudopanax, Schefflera e Sciadodendron (RECORD \& HESS, 1949), dos quais apenas Didymopanax e Pentapanax possuem espécies de interesse madeireiro na Floresta Estacional da bacia dos rios Paraná e Uruguai.

Didymopanax morototonii (Aubl.) Dcne. \& Planch. é árvore perenifólia, de 20 $30 \mathrm{~m}$ de altura, com tronco retilíneo de $60-90 \mathrm{~cm}$ de diâmetro e folhas palmatilobadas, compostas por 7 a 10 folíolos (LORENZI, 1992). Conhecida na Argentina por "ambay-guazú", recebe no Brasil os nomes de caixeta, paucaixeta, mandioqueira, pau-mandioca, mandiocão e morototó (REITZ et al., 1978). Com vasta área de dispersão, a espécie ocorre desde a América Central até o sul do Brasil e a Província de Misiones (Argentina), onde 
participa do estrato arbóreo superior da "selva misionera" (MUÑIZ, 1993). Sua madeira, leve $\left(0,53\right.$ a $\left.0,60 \mathrm{~g} / \mathrm{cm}^{3}\right)$, pouco resistente aos agentes biodeterioradores, permeável às soluções preservantes, de baixa retratibilidade e baixa a média resistência mecânica, indica-se para carpintaria geral, marcenaria, forros, lambris, esquadrias, guarnições internas, caixotaria leve, brinquedos, palitos de fósforo, miolo de portas, instrumentos musicais, cabos de vassoura, lápis, mobiliário, molduras, colheres para sorvete e a produção de lâminas (CARVALHO, 1994). As árvores preferem solos profundos, bem drenados e de boa fertilidade, encontrando-se por vezes em terrenos arenosos e pobres (INOUE et al., 1984).

Pentapanax warmingianus (March.) Harms também se destaca pelo grande porte de suas árvores, que alcançam até $25 \mathrm{~m}$ de altura e $80 \mathrm{~cm}$ de diâmetro, produzindo tronco reto, folhagem paucifoliada e grandes folhas compostas-imparipinadas, de folíolos serreados. Mais rara do que a espécie anterior, recebe os nomes de sabuguero, alamo, caroba-brava, sabuguerobravo, quino-quino, caroba-blanca e sauco-silvestre, na Argentina (BILONI, $1990)$ e de parapariguaçú ou carobão, no Brasil. Fornece madeira leve $(0,48$ $\mathrm{g} / \mathrm{cm}^{3}$ ), branco-amarelada, ligeiramente dura e de resistência média à flexão e ao choque, indicada para a confecção de lâminas e chapas. De grande potencial para reflorestamentos, a espécie destaca-se por ser de crescimento rápido e pelo bom desenvolvimento em capoeiras e capoeirões, comportando-se como pioneira (REITZ et al., 1983).

A estrutura anatômica das Araliáceas reúne poros geralmente em múltiplos radiais, pontoado intervascular escalariforme ou oposto, pontoações raio-vasculares grandes, elementos vasculares de comprimento médio a grande, parênquima paratraqueal usualmente escasso, fibras libriformes comumente septadas e raios heterogêneos, geralmente com 4 a 6 células de largura e mais de $1 \mathrm{~mm}$ de altura (METCALFE \& CHALK, 1972). As placas de perfuração podem ser simples ou escalariformes, tendo de poucas a numerosas barras grossas. RECORD \& HESS (1949) destacam a 
ausência de espessamentos espiralados nos vasos das espécies americanas da família e METCALFE \& CHALK (1972), observam a ocorrência de importantes semelhanças estruturais com as Umbelliferae, principalmente quanto ao parênquima paratraqueal e à presença de raios largos, providos de canais intercelulares.

A anatomia da madeira das Araliáceas sul-americanas é ainda pouco conhecida. Apesar desta generalização, cabe observar que TORTORELLI (1956) incluiu as duas espécies presentemente descritas em sua clássica obra sobre as madeiras argentinas. No Brasil, apenas Didymopanax morototonii foi pesquisada, quanto aos caracteres macroscópicos (STEIGLEDER, 1971) e propriedades tecnológicas de sua madeira (SILVA, 1967; JANKOWSKY et al., 1990; PEDROSO \& MATOS, 1987).

TORTORELLI (1956) observou uma grande semelhança anatômica entre as madeiras de Didymopanax morototonii e Pentapanax warmingianus, quanto à presença de porosidade difusa, de poros pequenos a medianos e em curtos múltiplos radiais (até 5 poros), de pontoações intervasculares muito grandes, de elementos vasculares médios a longos, de fibras libriformes com pequenas pontoações simples, de raios pouco numerosos e com geralmente 4 a 6 células de largura e de parênquima paratraqueal escasso. As principais diferenças, reportadas pelo autor, incidem na menor freqüência de poros $\left(18-20 / \mathrm{mm}^{2}\right)$ e na presença de placas escalariformes com até 5 barras, em Didymopanax morototonii e de placas raramente escalariformes, mas com poros mais numerosos $\left(20-45 / \mathrm{mm}^{2}\right)$, na madeira de Pentapanax warmingianus.

\section{MATERIAIS E MÉTODOS}

O material estudado consiste de 3 amostras de madeira para cada espécie, provenientes de uma floresta da Universidad Nacional de 
Misiones, localizada no departamento de Guaraní, Argentina. As referidas amostras foram extraídas de discos, tomados à altura do D.A.P. $(1,30 \mathrm{~m}$ do solo) e preferencialmente em região de alburno. O material lenhoso e respectivas exsicatas de material botânico, encontram-se arquivadas no Laboratório de Dendrologia, da Facultad de Ciencias Forestales, da Unversidad Nacional de Misiones.

Os corpos de prova para estudos anatômicos foram orientados para a obtenção de cortes nos planos transversal, longitudinal radial e longitudinal tangencial. Após o amolecimento, por fervura em água, procedeu-se o seccionamento dos mesmos em micrótomo de deslizamento, modelo Spencer AO no 860, com espessura variando de 14 a $24 \mu \mathrm{m}$. No tingimento dos cortes anatômicos utilizou-se o método de tripla coloração, com vermelho-de-acridina, crisoidina e azul-de-astra (DUJARDIN, 1964). Os cortes foram posteriormente desidratados em série alcoólica ascendente, diafanizados com xilol e montados em lâminas permanentes, com "Entellan".

Para a maceração dos tecidos seguiu-se o método de Jeffrey (FREUND, 1970), usando-se coloração apenas por safranina e o mesmo meio de montagem anteriormente referido.

Os dados quantitativos dos caracteres anatômicos foram processados diretamente no aparelho analisador de imagens "Videoplan", acoplado a um computador, obtendo-se desta forma os respectivos valores médios, máximos, mínimos e desvio padrão (s), com o uso de programas aplicativos.

As descrições macroscópicas seguiram a norma COPANT (1973). Para as descrições microscópicas e mensurações de elementos celulares individuais, seguiram-se as normas ABNT, com as alterações introduzidas por MUÑIZ (1986).

As fotomicrografias foram tomadas em foto-microscópio Carl Zeiss, tendo sido usado filme Kodak-Panatomic X, Asa 32, e ampliações em papel fotográfico Kodabromid F-3 brilhante. 


\section{DESCRIÇÃO DAS MADEIRAS}

\section{Didymopanax morototonii (Aubl.) Dene. \& Planch.}

Caracteres Gerais: Madeira de cerne esbranquiçado, com reflexos dourados e alburno mais claro. Textura de média a fina, heterogênea. Grã direita a oblíqua nas faces tangenciais. Figura suave a demarcada, principalmente nas faces radiais, onde se observa um listrado delicado e atrativo. Fácil de trabalhar, macia e leve, apresenta massa específica de 0,46 a $0,62 \mathrm{~g} / \mathrm{cm}^{3}$. Nas faces radiais destacam-se raios lenhosos castanho-claros sobre um fundo branco-amarelado, de tecido fibroso. Cheiro e gosto imperceptíveis. Superfície lustrosa e lisa ao tato.

Anéis de Crescimento: Demarcados pela presença de zonas fibrosas irregularmente espaçadas.

Vasos: Em porosidade difusa e de forma elíptica a circular, quando solitários. Predominam os múltiplos radiais curtos (2 a 3, raramente até 4 poros), com escassos racemiformes (Figura 1.A). Freqüência de 5 a 20 vasos por $\mathrm{mm}^{2}$. Elementos vasculares com lúmen de $60-115-150 \mu \mathrm{m}$ de diâmetro tangencial $(s=23,78)$ e $540-1150-1690 \mu \mathrm{m}(s=76,89)$ de comprimento. Apêndices com mais de $100 \mu \mathrm{m}$, presentes em uma ou ambas as extremidades. Placas de perfuração principalmente escalariformes (Figuras 1.C; 2.A), mas também simples e reticuladas (Figura 2. B). Pontoações intervasculares ornamentadas, alternas ou escalariformes, de forma poligonal, com abertura inclusa (Figura 2.C,D) e 9 - $14-25 \mu \mathrm{m}$ de diâmetro $(s=1,56)$. Pontoações raio-vasculares grandes, escalariformes $e$ arredondadas, de 13 a 31 um de diâmetro tangencial.

Parênquima axial: Escassamente paratraqueal e difuso, constituído por fileiras isoladas de células ou em pequenos agregados, formando quase um retículo. Séries parenquimáticas de 4 a 8 células. 
Raios: Heterogêneos, compostos por células procumbentes na parte central e células marginais quadradas e eretas (Figura 1.B). Células envolventes e canais secretores radiais, presentes. Variam de 280 - 766 $1380 \mu \mathrm{m}$ de altura por 40 - 95 - $170 \mu \mathrm{m}$ de largura, ocorrendo com freqüência de 2 a 6 raios $/ \mathrm{mm}$. Raios multisseriados (Figura 1.C,D), de 1 a 6 células de largura e com predominância dos tetrasseriados (62\%). Os raios multisseriados geralmente exibem canais intercelulares (Figura 1.D).

Fibras: Fibras libriformes e septadas (Figuras 1.D; 2.A,B), com pequenas pontoações simples, de seção quadrada a poligonal. Variam de $850-1650-2000 \mu \mathrm{m} \quad(s=131,12)$ de comprimento por 15,5 a $33,5 \mu \mathrm{m}$ de diâmetro externo, e com parede de 2,5 a $5 \mu \mathrm{m}$ de espessura.

\section{Pentapanax warmingiana (March.) Harms}

Caracteres gerais: Madeira de cerne e alburno não diferenciados, de cor uniforme, branco-palha a levemente amarelada e com brilho dourado na face radial, que muito a valoriza esteticamente. De textura média a homogênea, apresenta grã direita e figura suave na face tangencial; na face radial exibe um listrado mais suave do que o observado em Didymopanax morototonii, devido a seus maiores raios. Fácil de trabalhar e leve, apresenta massa específica variável entre 0,48 e $0,53 \mathrm{~g} / \mathrm{cm}^{3}$

Anéis de crescimento: De fracamente demarcados (Figura 3.A) a indistintos.

Vasos: Porosidade difusa (Figura 3.A). Poros de forma poligonal quando solitários, predominantemente em múltiplos radiais de 3 a 8 poros, com alguns geminados e agrupamentos racemiformes (Figura 3.A). Vasos com freqüência de 15 - $30-40$ por $\mathrm{mm}^{2}(\mathrm{~s}=4,67)$, com lúmen de 30 $140-195 \mu \mathrm{m}(s=21,09)$ de diâmetro tangencial e com paredes de 5 a 7,5 $\mu \mathrm{m}$ de espessura. Linhas vasculares levemente sinuosas. Elementos 

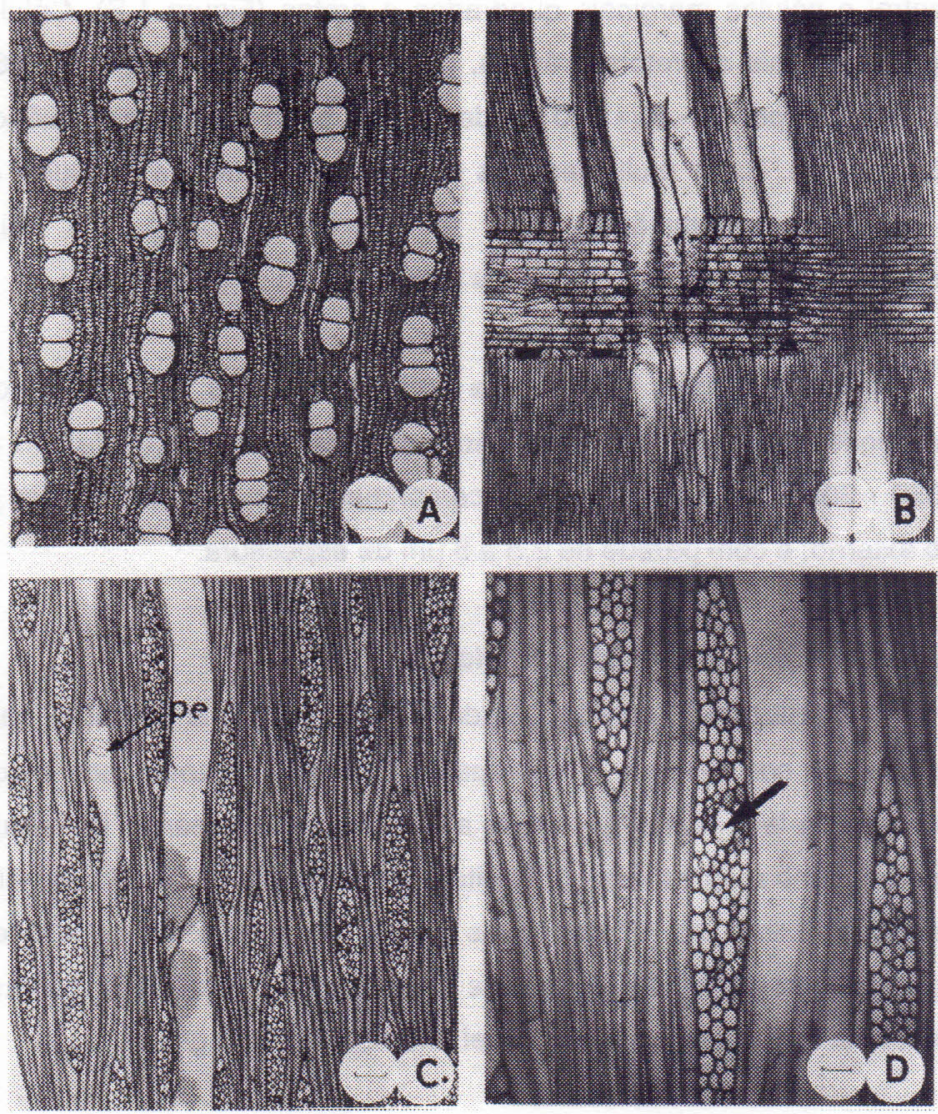

FIGURA 1. Didymopanax morototonii (Aubl.) Dene. \& Planch. A. Porosidade difusa, com poros solitários e em múltiplos radiais e racemiformes, em seção transversal (escala $=100 \mu \mathrm{m})$. B. Elementos de vaso, fibras septadas e tecido radial heterogêneo, constituído por células procumbentes, eretas e quadradas, em seção longitudinal radial (escala $=100 \mu \mathrm{m}$ ). C. Raios multisseriados e placa de perfuração escalariforme (pe), em seção longitudinal tangencial (escala $=100 \mu \mathrm{m})$. D. Canal secretor radial (seta) e fibras septadas, em seção longitudinal tangencial (escala $=40 \mu \mathrm{m})$.

vasculares de 600 - 1140 - $1350 \mu \mathrm{m}$ de comprimento, com apêndices de até $150 \mu \mathrm{m}$. Placas de perfuração verticais, predominantemente simples ou com 
1 a 3 perfurações por placa (Figura 4.A-C); placas escalariformes (Figura 4.D) ocasionais, irregulares ou com barras interrompidas. Pontoações intervasculares alternas (Figura 4.B), muito grandes (8 - $14-20 \mu \mathrm{m}$ ), poligonais, por vezes oblongas, e com abertura lenticular inclusa. Pontoações parênquimo-vasculares e raio-vasculares, semelhantes às intervasculares.
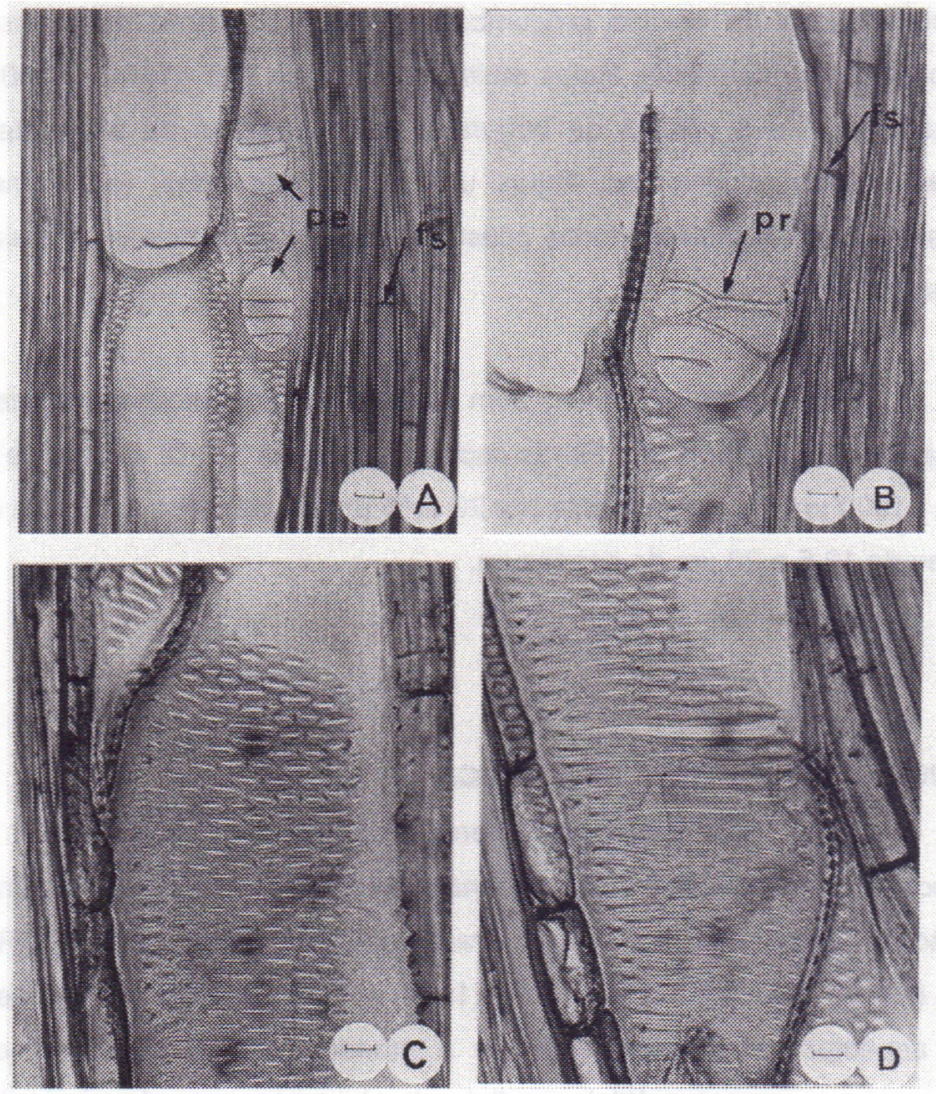

FIGURA 2. Didymopanax morototonii (Aubl.) Dcne. \& Planch. A. Placas de perfuração escalariformes (pe), em seção longitudinal radial (escala $=25 \mu \mathrm{m}$ ). B. Detalhe de placa reticulada (pr) e fibras septadas (fs), em seção longitudinal radial (escala $=12,5 \mu \mathrm{m}$ ). C., D. Pontoações intervasculares, alternas, grandes, arredondadas, escalariformes, ornamentadas e coalescentes, em seção longitudinal tangencial (escala $=12,5 \mu \mathrm{m}$ ) . 
Parênquima axial: Escassamente paratraqueal até difuso, constituído por fileiras isoladas de células ou formando pequenos agregados. Séries parenquimáticas formadas por 4 a 8 células.

Raios: Heterogêneos (Figura 3.B), com freqüência de 1 a 5 por $\mathrm{mm}$, constituídos de células procumbentes e até 5 fileiras marginais de células eretas e quadradas. Raios multisseriados, de $200-1100-1300 \mu \mathrm{m}$ de altura por 4 a 6 células de largura e até 60 células de altura, tendo grandes células envolventes. Raios uni, bi e trisseriados, relativamente escassos. Os raios multisseriados possuem frequentes canais intercelulares (Figuras 3.A-D).

Fibras: Libriformes, com numerosas pontoações simples ou inconspicuamente areoladas. Fibras septadas (Figuras 3.B-D; 4.A-D), de 800 - 1230 - $1500 \mu \mathrm{m}$ de comprimento por 20 a $55 \mu \mathrm{m}$ de diâmetro externo e com paredes de 12,5 a $26 \mu \mathrm{m}$ de espessura.

\section{ANÁLISE DA ESTRUTURA ANATÔMICA}

Os principais caracteres anatômicos observados em Didymopanax morototonii e Pentapanax warmingianus correspondem ao descrito na literatura para a família Araliaceae, de acordo com RECORD \& HESS (1949), METCALFE \& CHALK (1972) e TORTORELLI (1956). Dentre estes aspectos anatômicos, citam-se a presença de poros pequenos a médios e em pequenos múltiplos radiais, de elementos vasculares médios a longos e com pontoações muito grandes, de fibras libriformes com pequenas pontoações simples, de parênquima paratraqueal escasso e de raios heterogêneos, com 4 a 6 células de largura e freqüentes canais intercelulares. 

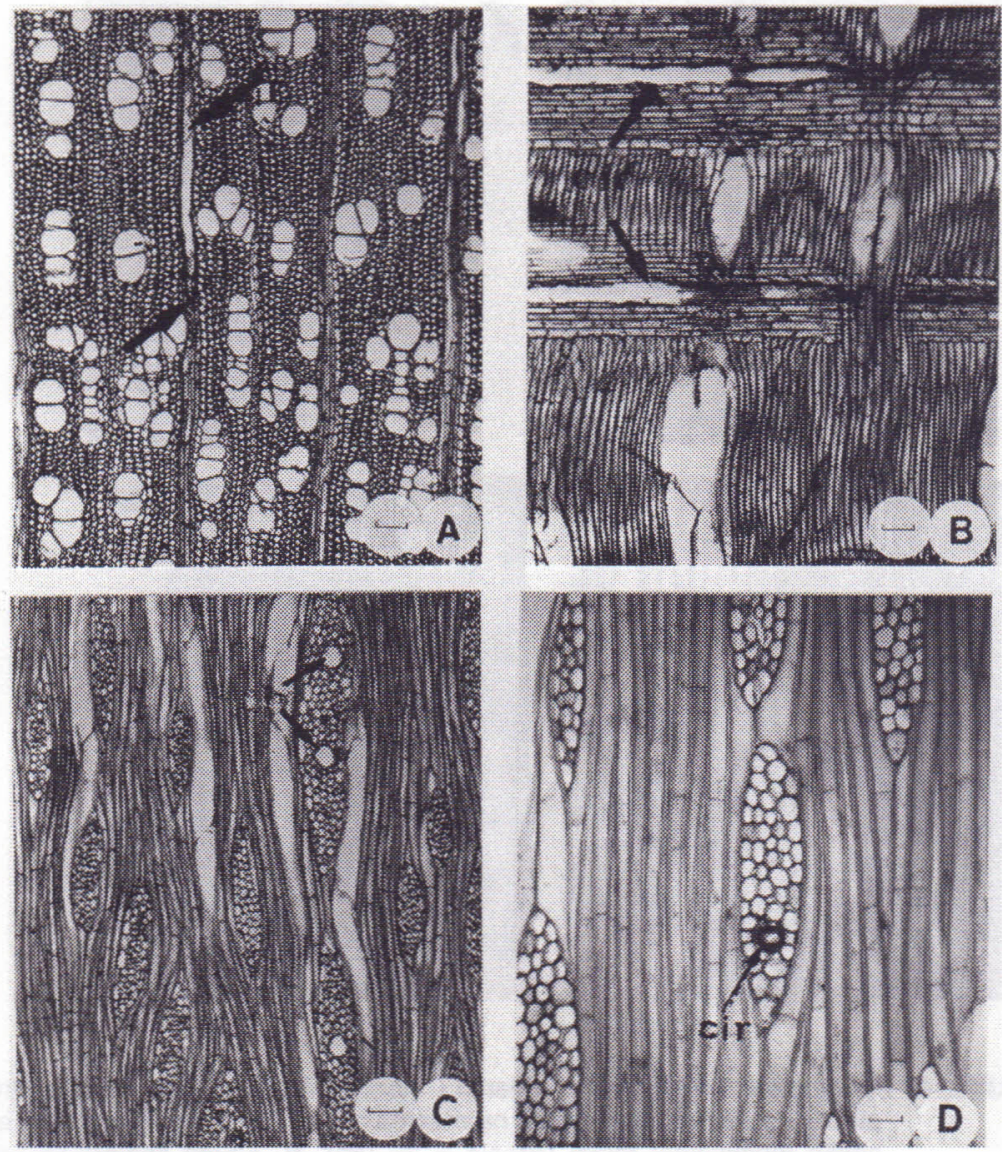

FIGURA 3. Pentapanax warmingianus (March.) Harms. A. Poros solitários, em múltiplos radiais e canal intercelular radial (seta), em seção transversal (escala $=100 \mu \mathrm{m}$ ). B. Raios com canais intercelulares radiais (seta), tecido radial heterogêneo e fibras septadas, em seção longitudinal radial (escala $=100 \mu \mathrm{m})$. C. Canais intercelulares radiais (seta) e fibras septadas, em seção longitudinal tangencial (escala $=100 \mu \mathrm{m})$. D. Detalhe de canal intercelular radial (cir), em raio multisseriado (escala = $25 \mu \mathrm{m})$. 

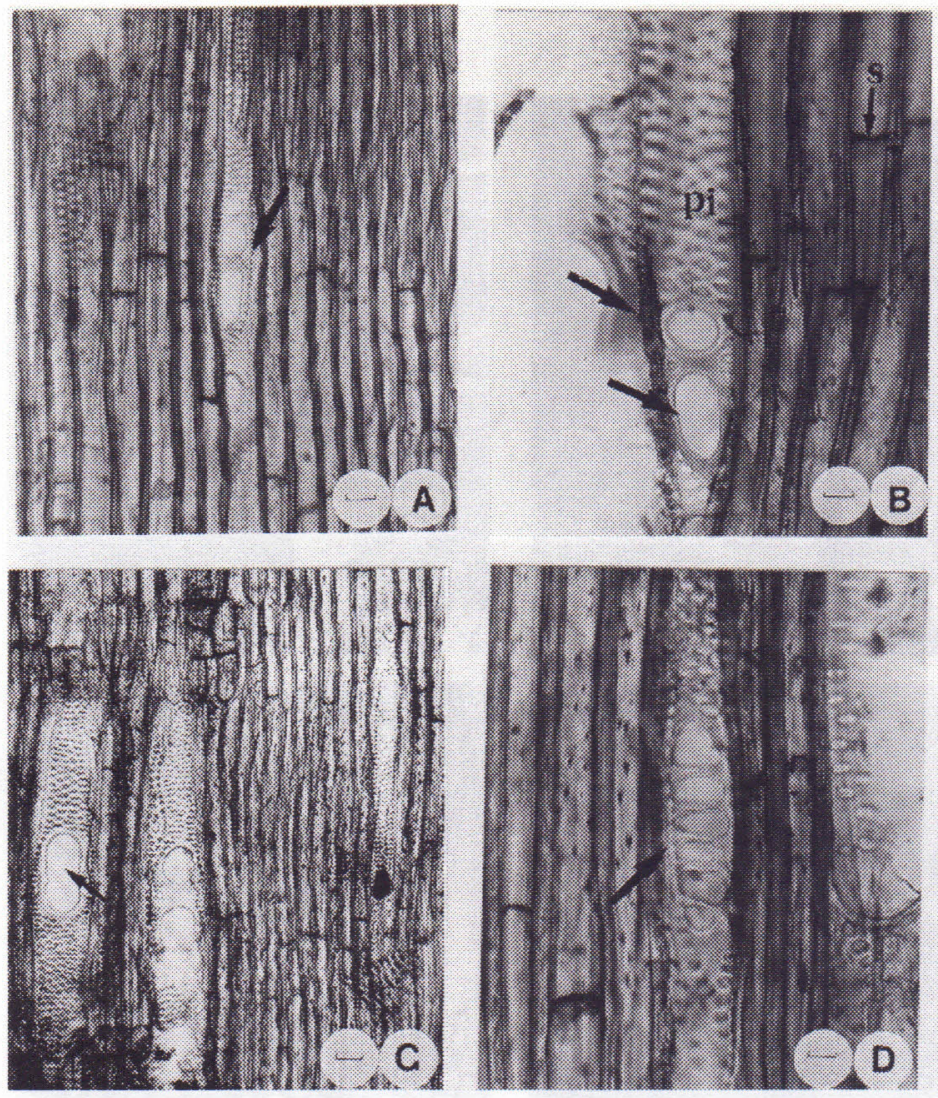

FIGURA 4. Pentapanax warmingianus (March.) Harms. A. Fibras septadas e três placas de perfuração simples na mesma extremidade de vaso (seta), em seção longitudinal radial (escala $=25 \mu \mathrm{m}$ ). B. Fibras libriformes com septos (s); elementos de vaso com duas placas de perfuração (escala = $12,5 \mu \mathrm{m})$. C. Placa de perfuração irregular (seta), em seção longitudinal radial (escala $=40 \mu \mathrm{m})$. D. Detalhe de placa de perfuração escalariforme (seta), em seção longitudinal radial (escala $=12,5 \mu \mathrm{m})$.

A porosidade difusa, observada nas duas espécies em estudo, corresponde ao referido na literatura para as Araliáceas do Hemisfério Sul, pois a porosidade em anel foi registrada apenas em espécies de regiões temperadas do Hemisfério Norte (METCALFE \& CHALK, 1972).

154 Rev. Ciência e Natura, Santa Maria, 19: 143 - 157, 1997 
A ausência de espessamentos espiralados nas duas madeiras, concorda com o observado por METCALFE \& CHALK (1972), para as espécies neotropicais da família. A ocorrência simultânea de placas simples e múltiplas, é igualmente peculiar à família Araliaceae, segundo os mesmos autores.

A distinção anatômica entre as espécies analisadas pode ser facilmente realizada através da análise das pontoações intervasculares e das placas de perfuração. Quanto a este último caráter, tem-se a observar que TORTORELLI (1956) já havia distinguido as duas espécies em questão.

Resta observar que os vasos de Didymopanax morototonii apresentam pontoações predominantemente escalariformes e ornamentadas, com placas de perfuração escalariformes, simples ou reticuladas. Já em Pentapanax warmingianus, as pontoações não são ornamentadas, possuem forma arredondada ou poligonal e predominam placas de perfuração simples, ocorrendo mais raramente placas escalariformes.

\section{CONCLUSÕES}

A análise da estrutura anatômica das madeiras de Didymopanax morototonii e Pentapanax warmingianus indica as seguintes conclusões:

- As duas madeiras apresentam o conjunto de caracteres anatômicos peculiar à família Araliaceae: poros pequenos a médios e em curtos múltiplos radiais, pontoações intervasculares grandes, elementos vasculares médios a longos, placas de perfuração simples e múltiplas, fibras libriformes, parênquima paratraqueal escasso e raios heterocelulares, providos de canais intercelulares.

- O exame anatômico possibilita uma fácil separação entre as duas madeiras estudadas. 
- Didymopanax morototonii distingue-se pela ocorrência de placas de perfuração geralmente escalariformes e de pontoações intervasculares ornamentadas, em arranjo freqüentemente escalariforme.

- Pentapanax warmigianus separa-se da anterior pela ausência de ornamentações nas pontoações intervasculares, pelo arranjo alterno ou oposto de suas pontoações arredondadas ou poligonais e pela predominância de placas de perfuração simples nos vasos.

\section{LITERATURA CITADA}

BILONI, J.S. Arboles Autoctonos Argentinos. Buenos Aires: Tipográfica Editora Argentina, 1990. $335 \mathrm{p}$.

CARVALHO, P.E.R. Espécies Florestais Brasileiras - Recomendações Silviculturais, Potencialidades e Uso da Madeira. Colombo: EMBRAPACNPF/SPI, 1994. 639 p.

COPANT - COMISSÃO PANAMERICANA DE NORMAS TECNICAS.

Descrição macroscópica, microscópica e geral da madeira - esquema I de recomendação. Colômbia, 1973. 19 p. (COPANT 30).

DUJARDIN, E.P. Eine neue Holz-zellulosenfaerbung. Mikrokosmos, n. 53, p. 94, 1964.

FREUND, H. Handbuch der Mikroskopie in der Technik. Frankfurt: Umsham Verlag, 1970. 375 p.

INOUE, M.T., RODERJAN, C.V., KUNIYOSHI, Y.S. Projeto Madeira do

Paraná. Curitiba: Fundação de Pesquisas Florestais do Paraná, 1984. $260 \mathrm{p}$.

JANKOWSKY. I.P., CHIMELO, J.P., CAVALCANTE, A. de A., GALINA, I.C.M., NAGAMURA, J.C.S. Madeiras Brasileiras. Caxias do Sul: Spectrum, 1990. $171 \mathrm{p}$. 
LORENZI, H. Árvores Brasileiras - Manual de Identificação e Cultivo de Plantas Arbóreas Nativas do Brasil. Nova Odessa: Ed. Plantarum, 1992. $352 \mathrm{p}$.

MELCHIOR, H. Reihe Umbelliflorae. In: MELCHIOR, H. A. Engler's Syllabus der Pflanzenfamilien. Berlin: Gebrüder Borntraeger, 1964. v. 2. 666 p.

METCALFE, C.R., CHALK, L. Anatomy of the Dicotyledons. Oxford: Clarendon Press, 1972. 1500 p.

MUÑIZ, G.I.B. Descrição da estrutura e ultraestrutura da madeira de cinco espécies de Prosopis da Argentina e análise da metodologia.

Curitiba, Curso de Pós-Graduação em Engenharia Florestal, 1986. 192 p. Dissertação de Mestrado.

MUÑIZ, G.I.B. Anatomia da Madeira de Espécies Arbóreas da Floresta

Estacional Semidecidual de Misiones, Argentina. Curitiba, Universidade Federal do Paraná, 1993. 152 p. Tese para concurso de Professor Titular, Departamento de Engenharia e Tecnologia Rurais.

PEDROSO, O., MATTOS, J.R. Estudo sobre Madeiras do Rio Grande do

Sul. Porto Alegre, Instituto de Pesquisas de Recursos Naturais Renováveis "Ataliba Paz", 1987. Bol. n. 20.181 p.

RECORD, S.J., HESS, R.W. Timbers of the New World. New Haven: Yale University Press, 1949. 640 p.

REITZ, R., KLEIN, R.M., REIS, A. Projeto Madeira de Santa Catarina. Sellowia, Itajaí, n. 28-30, p. 1-320, 1978.

REITZ, R., KLEIN, R.M., REIS, A. Projeto Madeira do Rio Grande do Sul. Sellowia, Itajaí, n. 34-35, p. 1-525, 1983.

SILVA, P.F. da. Características Físico-Mecânicas de Espécies Lenhosas do Sul do Brasil. Porto Alegre, Instituto Tecnológico do Rio Grande do Sul, 1967. Bol. n. 42.41 p.

STEIGLEDER, M. de V. Madeiras do Sul do Brasil. Porto Alegre, ITERS, 1971. Bol. n. 54. 59 p.

TORTORELLI, L.A. Maderas y Bosques Argentinos. Buenos Aires: ACME, 1956. $910 p$ 
158 Rev. Ciência e Natura, Santa Maria, 19: 143 - 157, 1997 